\title{
O PRIAPEUM 3 DO APENNDICE VIRGILIANO EM VERSO PRIAPEU EM PORTUGUÊS
}

\section{THE PRIAPEUM 3 OF THE APPENDIX VERGILIANA IN PRIAPEUM VERSE IN BRAZILIAN PORTUGUESE}

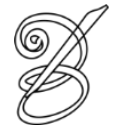 \\ Marina Cavichiolo GROCHOCKI ${ }^{\mathrm{i} *}$ \\ University of Wisconsin-Madison \\ Madison, Wisconsin, Estados Unidos
}

Resumo: É proposta uma tradução para o poema Priapeum 3 da coletânea do Apêndice Virgiliano, recriando o ritmo do verso priapeu através da oposição de sílabas tônicas e átonas no português, em um verso de quatorze sílabas poéticas.

Palavras-chave: Priapeum. Apêndice Virgiliano. Priapeu. Tradução poética. Priapo.

Abstract: A translation of the poem Priapeum 3 of the Appendix Vergiliana is given, recreating the rhythm of the priapeum verse through the opposition of stressed and unstressed syllables in Portuguese, in a line of fourteen poetic syllables.

Keywords: Priapeum. Appendix Vergiliana. Priapeum. Poetic translation. Priapus.

RECEBIDO EM: 3 de setembro de 2019

ACEITO EM: 25 de novembro de 2019

PUBLICADO EM: março 2020

GROCHOCKI, Marina. O Priapeum 3 do Apêndice Virgiliano em verso priapeu em português. Belas Infiéis, Brasília, v. 9, n. 2, p. 125-128, 2020. 

Priapeum 3 faz parte tanto da Priapea latina quanto do Apêndice Virgiliano, ambas coletâneas de poemas espúrios em determinado momento atribuídas a Virgílio. Por mais que hoje não existam dúvidas sobre a não autoria do mantuano em relação a esses poemas, a utilização de elementos também mencionados no cenário campestre das Bucólicas e das Geórgicas pode ser um ponto interessante a se considerar sobre esses poemas que permanecem (e, ao que tudo indica, permanecerão) sem um autor definido.

O Priapeum 3 é em verso priapeu (com 15 sílabas, no seguinte esquema de sílabas longas e breves: $-\mathrm{x}-\mathrm{u} \mathrm{u}-\mathrm{u}-\|-\mathrm{u}-\mathrm{u} \mathrm{u}--$, havendo uma cesura entre a oitava e a nona sílaba) e foi traduzido em tentativa de recriar o ritmo desse verso. Assim, as sílabas tônicas no verso em português acompanham as longas do verso em latim: no latim há sílabas longas obrigatórias nas posições silábicas 1, 3, 6, 8, 9, 11 e 14, de modo que o verso em português tem quatorze sílabas poéticas, com sílabas tônicas ou monossílabos (podendo estes ser átonos) nessas posições. No entanto, em alguns versos não foi possível manter a tônica inicial ou póscesura (posição um e nove), como nos versos 12 e 20 . No momento de oralização do poema, isso seria resolvido através de uma leitura enfática dessas sílabas, mesmo que átonas. $\mathrm{O}$ 126 espaçamento dentro de um mesmo verso indica a cesura obrigatória, sinalizando a quebra gerada pelo encontro de duas sílabas tônicas e reforçando a necessidade dessa leitura enfática também quando isso não ocorre na tradução (verso 20). Paroxítonas sempre finalizam os versos, de modo que há no português uma emulação para as duas últimas sílabas do verso em latim. Para manter ritmo (com esquema rígido de tonicidade das palavras), foram feitas algumas inversões sintáticas.

Parte da tradução de Oliva Neto (2006, p. 253) para o verso 13 (pallentesque cucurbitae et suaue olentia mala, "brancas abóboras, maçãs de suave olor”) funcionava também na proposta rítmica aqui seguida e, assim, a solução dele é também utilizada no início do verso 13 aqui ("e as maçãs de suave olor e as abóboras frescas"). 


\section{PRIAPEIA 3}

Ó meninos, eu nutro tal casa e horta palustre,

por figueiras em feixe e até vime e junco coberta;

eu, um seco carvalho, um pau para agreste machado, nutro: torna-se cada vez mais beata a cada ano.

5 Pois os donos me adoram aqui, deus também me celebram, tanto o pai da cabana vil quanto o filho mancebo, um, com preocupações, tenaz para que, ásperas, ervas e silvados do templo meu sejam já removidos; o outro com generosa mão poucas graças trazendo.

10 Em florida estação em mim põe guirlanda pintada, antes verdes espigas já junto de tenro cabelo; violeta amarela em mim, cor de leite papoula e as maçãs de suave odor e as abóboras frescas; uva rubra, domada sob sombra dessa videira.

15 Esse meu armamento (mas vos calai), sim, com sangue suja a cabra menor de pé córneo e o bode barbado. Por tais honras, Priapo olhar deve já para tudo, e a hortinha do seu senhor proteger, com as parreiras. Ó rapazes, por isso maus roubos longe mantende:

20 perto um rico vizinho está, desatento a Priapo.

Vós, roubai de lá: leva-vos lá o mesmo caminho. 


\section{PRIAPEUM 3}

Hunc ego, o iuuenes, locum uillulamque palustrem

tectam uimine iunceo caricisque maniplis,

quercus arida rustica fomitata securi

nutrior: magis et magis fit beata quotannis.

5 huius nam domini colunt me, deumque salutant

pauperis tuguri pater filiusque adulescens,

alter assidua cauens diligentia, ut herbae,

aspera ut rubus a meo sit remota sacello,

alter parua manu ferens semper munera larga.

10 florido mihi ponitur picta uere corolla,

primitus tenera uirens spica mollis arista,

luteae uiolae mihi lacteumque papauer

pallentesque cucurbitae et suaue olentia mala,

uua pampinea rubens educata sub umbra;

128 sanguine haec etiam mihi (sed tacebitis) arma

barbatus linit hirculus cornipesque capella.

pro quis omnia honoribus nunc necesse Priapo est

praestare, et domini hortulum uineamque tueri.

quare hinc, o pueri, malas abstinete rapinas:

20 uicinus prope diues est neglegensque Priapi.

inde sumite: semita haec deinde uos feret ipsa.

\section{REFERÊNCIA}

RICHMOND, J. A. et al. Appendix Vergiliana. Oxford Classical Texts, 1966.

\footnotetext{
i* Marina Cavichiolo GROCHOCKI - Licenciada em Letras - Português (2016) e Bacharel em Letras - Latim (2018) pela Universidade Federal do Paraná. Mestre em Letras (2019) pela mesma instituição. Doutoranda em Clássicas na Universidade de Wisconsin-Madison, Estados Unidos. University of Wisconsin in Madison, Department of Classical and Ancient Near Eastern Studies. Madison, Wisconsin, Estados Unidos.

Currículo acadêmico: http://lattes.cnpq.br/7940859286740784 https://canes.wisc.edu/staff/grochocki-marina/

ORCID: https://orcid.org/0000-0002-6591-3383

E-mail: marinagrochocki@gmail.com

mgrochocki@wisc.edu
} 